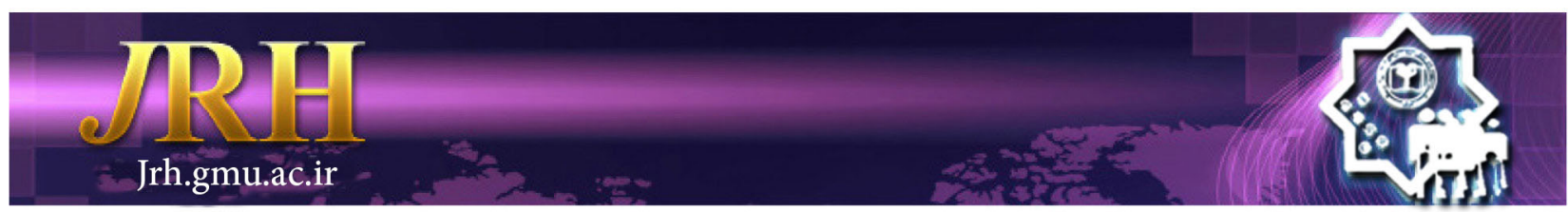

\title{
The relationship between parenting styles and compatibility in high school female students in Mashhad
}

Toktam Kazemeini ${ }^{1}$, Farideh Nazarzadeh ${ }^{1}$, Mahbobe Dehghan ${ }^{2}$

\author{
Journal of Research \& Health \\ Social Development \& Health Promotion \\ Research Center \\ Vol. 8, No.5, Sep \& Oct 2018 \\ Pages: $403-410$ \\ DOI: $10.29252 / j r h .8 .5 .403$ \\ Original Article
}

1. Department of Psychology, Faculty of Educational Sciences and Psychology, Ferdowsi University of Mashhad, Iran

2. Department of Clinical Psychology, School of Education Sciences, Islamic Azad University, Torbat-e-Jam, Razavi Khorasan, Iran

Correspondence to: Farideh Nazarzadeh, Department of Psychology, Faculty of Educational Sciences and Psychology, Ferdowsi University of Mashhad, Iran

Email: Nazarzadeh1986@gmail.com

Received: 8 Nov 2013

Accepted: 9 Mar 2014

How to cite this article: Kazemeini $\mathrm{T}$, Nazarzadeh F, Dehghan M. the relationship between parenting styles and compatibility in high school female students in mashhad. $J$ Research \& Health2018; 8(5): 403- 410.

\begin{abstract}
Considering parenting styles and quality of relationships between parents and adolescents are important factors in their compatibility, the present study investigated the relationship between parenting styles and compatibility of students. According to the multi stage cluster sampling, 243 high school students were recruited for the study. The study tools were Baum rind's parenting styles questionnaire and adjustment inventory for school students. The ANOVA showed a significant difference between emotional, social and academic adjustment in students nurtured with authoritative, authoritarian, and permissive parenting styles. Based on the results, students nurtured with authoritative parenting style were more compatible emotionally socially and academically, while the lowest compatibility was observed among students nurtured with authoritarian and permissive parenting styles, respectively. In families with authoritative parenting style, parents give opportunities to the teens that would strengthen them in decision-making and autonomy. The authoritative parenting style helps the psychological maturity of adolescent, leading to better adaptation.
\end{abstract}

Keywords: Academic, Emotional, Social Maladjustment, Parenting

\section{Introduction}

Family is the first and the most important environment in which a child becomes aware of human relationship quality and it is the basis of individuals' thought characteristics, values and criteria [1]. The child inherits some of his/her parents' characteristics, but parents' role does not become restricted to genetic aspects. Parents' criteria and favorites and their parenting style all can play a significant role in forming the child's behavior, mental health, and socialemotional compatibilities [2].

Often with the onset of physical maturity, the relationships of adolescents with family, school counselors and people of the society 
would be changed and it seems that they would be converted into another creature. Physical maturity that is followed by changing in adolescents' behaviors, emotional needs, internal emotions and social mood inevitably can lead to conflicts in their relationships with environment and others. Many dangerous behaviors such as misdemeanor, substance and alcohol abuse and vulnerable sexual relationship may occur during this period of maturity. Although many youth pass the adolescence successfully without encountering any important problem, by entering to the second decade of life, the rest of the mare faced with increased misdemeanor danger and risky behaviors for health. The involvement in misdemeanor and perilous behavior for health can potentially prevents a person in adolescence to have a positive and successful path, instead, it puts him/her in a path, which is specified by negative line routes that can result in lower optimal performance and create the base of incompatibility (inadaptability) [3].

Parenting styles refers to the methods which are employed by parents in dealing with their children [4]. According to Baum rind, three basic parenting styles are defined: authoritarian, permissive and authoritative. These parenting styles are different in two characteristics; how much attention and warmth a child receives and how much a child's behavior and activity is controlled [5].

Performed researches in this field, imply that parenting styles and parents' behaviors are related to adolescents' behavioral problems and incompatibilities [6] and using the correct styles of parenting by parents has significant effects on preventing from incompatibility [7].

According to the results of Darling's research [3], children and adolescents of authoritarian families have average scores at school and less confidence, suffer from high level of depression, and have weak academic and emotional compatibility (adaptability). Also, Sohrabi and hasani [8] showed the contribution of authoritarian style of parenting and family disunity to the anti-social behaviors of adolescents. Inappropriate parents have very high and very low expectations of their children and these expectations are not proper for the child and his/her position and can increase the risk of anomalies and incompatibility for the child [9].

Psychologists believe that a person's compatibility includes a set of normal characteristics shown by people toward environment and make them create compatibility with their world [10]. The quality of relations between parents and adolescents and also the parenting style are of determinant factors of their compatibility. Parents' manner of interaction with children and adolescents and the mental-emotional atmosphere governing the family form the personal characteristics and behavior of the offspring. Extremes in contexts such as acceptance, freedom, expectations and encouraging to inappropriate and criminal acts have an important role in creating adolescents' behavioral problems. Incorrect relationships with a child by his/her family members in the form of rejection by parents, lack of physical stroking, denying kindness, lack of attention to activities and improvements, hard punishment for small mistakes, absence in spending time with child, and lack of attention to child's rights and emotions as a person have been enumerated as impressive resources in insufficient maturity and the formation of incompatibility in a person [8]. Children who live with tumultuous families mostly show aggression and do other harsh behaviors when facing problems and as a result, certain social skills would be decreased in such children. The behavioral disorders of children, which are typically revealed as incompatibility of children's abnormal, amoral or anti-social behaviors, are created due to the parents' nurture and treatment styles [11].

Despite the significant rise of conducted researches in this field in recent years, most of them were concentrated on mothers' nurture style and childhood and less paid attention to adolescence; as a result, in this study, we investigated the parenting styles relationship with adolescents' compatibility. Consequently, as parenting styles have a significant role in adolescents' compatibility and incompatibility, 
and considering that perceiving this role requires investigating the existent relationships between the parenting styles and the appearance of adolescents' abnormal behaviors, the present work aimed to investigate the role of parenting styles in social, emotional and educational compatibility of adolescents.

\section{Method}

The present research was descriptive in the type of causal-comparative. The study population comprised all of high school girl students in Mashhad who were enrolled in the 2012-2013. According to the Morgan's equation and multistep cluster sampling method, a sample consisted of 243 students was selected out of a total of 2000 persons. After conducting required coordination with Khorasan Razavi Department of Education and receiving required permission, at first among seven areas of Mashhad Department of Education, area 2 was selected randomly and then, from that area, one school was chosen randomly. Upon referring to the considered school, among 30 classes in both morning and evening shifts, 8 classes were selected randomly that included 243 students.

In this research tools included:

Parenting Styles Questionnaire (PSQ) Baum rind: This questionnaire was created by Diana Baum rind in 1973 as an especial scale for parents. It is composed of 30 items; 10 items for measuring the permissive style (sentences 1, $6,10,13,14,17,19,21,24,28), 10$ other items for measuring the authoritariandtyle (sentences $2,3,7,9,12,16,18,25,26,29)$ and the rest of the items for measuring the authoritativestyle (sentences 4, 5, 8, 11, 15, 20, 22, 23, 27, 30). For each item, a 5-point scale from "completely agree" to "completely disagree" was used to score responses from 0 to 4 [10]. For each of the parenting styles, the least and the highest scores were 0 and 40, respectively. The highest score in style indicates the agreement of respondent with that style. The style possessing the highest score was the parent's dominant parenting style. Bori has reported the reliability of this questionnaire using a test-retest method among mothers' group as follows; 0.81 for permissive method,
0.86 for authoritarian method, and 0.78 for authoritative method. Also, the reliability coefficients among fathers' group were: 0.77 for permissive method, 0.78 for authoritarian method, and 0.92 for authoritative method. Esfandiari also confirmed the reliability of this test through test-retest method using the interval of one week as follows: 0.69 for permissive method, 0.77 for authoritarian method, and 0.73 for authoritative method. The validity of the test content has been also confirmed by 10 psychologists and psychiatrists [12].

Adjustment Inventory for School Students (AISS): This questionnaire was designed to determine the social, emotional and educational compatibility of the students. It is consisted of 60 questions; 40 items were considered to measure the emotional and social areas, while the educational area was addressed by the rest of the items. The items were designed as yes or no questions. In this questionnaire, for answers indicating the compatibility in three areas, score of zero was considered; otherwise, the score was one. For subjects, 5 categories with corresponding amplitude of scores were obtained in emotional, social and educational areas, based on the raw scores obtained from the Likert scale. The validity coefficient for each question was determined using biserial correlation, just for questions which their biserial correlations were confirmed at significance level of $p=0.001$ [13]. Finally, the data were analyzed with SPSS-16 using Oneway Analysis of Variance (One-way ANOVA) statistical method and Scheffe Post Hoc test. It must also be noticed that according to the Kolmogorov-Smirnov test, considered data had normal distribution. Moreover, according to the assumed Levine test, the equality of the variances was satisfying, meaning that the variances of the three groups were equal and as a result, they were comparable $(\mathrm{p}<0.05)$.

\section{Results}

In this study, 16-18 year old high school girl students with mean age of (15.72 \pm 2.71$)$, years were studied. The descriptive findings regarding parenting styles demonstrated that 
the mean of authoritative parenting style was (89.44 \pm 3.11$)$, while it was $(22.92 \pm 6.19)$, for authoritarian parenting style and $(84.91 \pm 5.62)$, for the permissive one.

According to Table 1, there was a significant difference between three groups of the students in terms of the total score of compatibility, so, the main theory was confirmed. In other words, there was a significant difference between total compatibility of the students nurtured with different parenting styles including authoritarian, authoritative and permissive
$(\mathrm{F}=17.9$ and $\mathrm{p}<0.00)$. According to the obtained results in Table 2, the highest compatibility was observed for the students nurtured with authoritative style of parenting, while the least compatibility was reported for the students nurtured with authoritarian and permissive styles of parenting, respectively. In order to test the hypothesis that there can be a significant difference between the social compatibility of the students nurtured with various parenting styles including authoritarian, authoritative and permissive, the one-way ANOVA was used.

Table1 The one-way ANOVA results of total compatibility in three groups

\begin{tabular}{lccccc}
\hline $\begin{array}{l}\text { Source of } \\
\text { dispersion }\end{array}$ & Sum of squares & Degree of freedom & Mean Square & F & p-value \\
\hline ssb & 966.7 & 2 & 483.9 & 17.9 & 0.00 \\
ssw & 59.14 & 240 & 231.6 & & \\
\hline
\end{tabular}

Table 2 The difference of three groups in terms of total compatibility based on the Scheffe Post Hoc test

\begin{tabular}{lc}
\hline Group & Mean \\
\hline Authoritative & 0.58 \\
Authoritarian & 0.38 \\
Permissive & 0.29 \\
\hline
\end{tabular}

As shown in Table 3, there was a significant difference between social compatibility of students nurtured with authoritarian, authoritative and permissive styles of parenting $(\mathrm{F}=9.119$ and $\mathrm{p}<0.001)$.

Also, as shown in Table 4, in terms of emotional compatibility score, there was a significant difference between three groups of students. So, this hypothesis is confirmed. In other words, there was a significant difference between emotional compatibility of the students nurtured with different styles of parenting including authoritarian, authoritative and permissive $(\mathrm{F}=11.06$ and $\mathrm{p}<0.001)$.

Table 3 The results of one-way ANOVA of social compatibility in three groups

\begin{tabular}{lccccc}
\hline $\begin{array}{l}\text { Source of } \\
\text { dispersion }\end{array}$ & Sum of Squares & Degree of freedom & Mean Square & F & p-value \\
\hline ssb & 423.7 & 2 & 419.9 & 9.11 & 0.001 \\
ssw & 23.14 & 240 & 39.6 & & \\
\hline
\end{tabular}

Table 4 The results of one-way ANOVA of emotional compatibility in three groups

\begin{tabular}{lccccc}
\hline $\begin{array}{l}\text { Source of } \\
\text { dispersion }\end{array}$ & Sum of Squares & Degree of freedom & Mean Square & F & p-value \\
\hline ssb & 319.7 & 2 & 329.9 & 11.06 & 0.001 \\
ssw & 19.14 & 240 & 18.6 & & \\
\hline
\end{tabular}

Finally, the results of one-way ANOVA showed that there was a significant difference between educational compatibility of the students nurtured with various styles of parenting including authoritarian, authoritative and permissive $(\mathrm{F}=7.19$ and $\mathrm{p}<0.001)$. According to the obtained results in Table 8 , students nurtured with authoritative style of parenting had the highest educational compatibility and those who were nurtured with authoritarian and permissive styles of parenting had the lowest educational compatibility. 
Relationship between parenting styles and compatibility

Table 5 The results of One-way ANOVA of educational compatibility in three groups

\begin{tabular}{lccccc}
\hline $\begin{array}{l}\text { Source of } \\
\text { dispersion }\end{array}$ & Sum of squares & Degree of freedom & Mean square & F & p-value \\
\hline ssb & 511.9 & 2 & 618.3 & 7.19 & 0.001 \\
ssw & 18.11 & 240 & 22.03 & & \\
\hline
\end{tabular}

\begin{tabular}{lc}
\multicolumn{2}{l}{ Table 6 Scheffe's pair wise comparison in the posttest of triple groups } \\
\hline Group & Mean \\
\hline Authoritative & 0.61 \\
Authoritarian & 0.43 \\
Permissive & 0.39 \\
\hline
\end{tabular}

\section{Discussion}

The results showed that students nurtured with authoritative style of parenting had the highest emotional, social and educational compatibility and those who were nurtured with authoritarian and permissive styles of parenting had the lowest compatibility.

This result was in agreement with the findings of Amanallahifard et al. [14], Farzigolfazani et al. [15], Sohrabi and Hasani [8], Rajabi et al. [7], Comijani and Maher [9], Ahangranzabi et al. [16], Khanjani et al. [17], Pakdaman et al. [12], Geram et al. [11]. In order to explain this result, it could be expressed that parents with authoritative style of nurturing are both receptive and responder and are at high levels of demandingness and control. They deduct explicit and specified rulesand enforce the children to perform and execute them, and they explain the fundamental principles of the rules and limitations. These parents are compatible with growing needs of children and give high value to the growth of their autonomy [18]. Parents in this style give opportunities the children to strengthen them in decision making and independence. In fact, the decisive and crucial parenting helps form the psychological maturity in adolescents which results in a better compatibility. But in authoritarian style, parental control and demandingness is high and their receptivity-responsiveness is low. This group is non-supporting and does not pay any attention to the children's independence. The permissive parents have high receptivityresponsiveness and low demandingness and control. They are so much tolerant toward their children's behaviors, have less controlling state on their behaviors, and encourage them to explain their feelings and motivations [15]. The results of variance analysis showed that the social compatibility of students nurtured with authoritative style was significantly more than the social compatibility of the students who were nurtured with authoritarian and permissive styles, while the social compatibility of the students who were nurtured with authoritarian style was significantly more than the social compatibility of the students corresponding to the permissive style. This result was in agreement with the research findings of Sohrabi and Hasani [8], Comijani and Maher [9], Amanallahifard et al. [14], Ahangranzabi et al. [16], Pakdaman et al. [12], Geram et al. [11], SaefiGandomani et al. [19], Baumrind [5], Hui et al. [20] and Carla et al. [21].

In order to explain this finding, it can be expressed that in families with permissive style of parenting, the lack of parents' control or supervision leads to the adolescence tendency toward incompatibility and social deviation. In families with authoritarian style of parenting, the parents 'very high and inappropriate expectations and their disregard, disinterest, and low emotional involvement toward their children, all increase the risk of social harshness for the adolescences [11]. Also, over-supportive behavior of parents in authoritarian style prevents the child from independence and causes his/her separation from social experiences and this, in turn, causes harm to acquisition of social skills and social crudity for adolescents, as well. 
Also, the results of data analysis revealed that emotional compatibility of the students nurtured with authoritative style was significantly more than the emotional compatibility of the students nurtured with authoritarian and permissive styles, while emotional compatibility of the students nurtured with permissive style was significantly more than the compatibility of the students nurtured with authoritarian style.

This result was in agreement with the research findings of Farzigolfazani et al. [15], Amanallahifard et al. [14], Khanjani et al. [17], Geram et al. [11], SaefiGandomani et al. [19], Baumrind [5], Urban, Carelson, Egeland and Sroufe [22], Darling and Steinberg [4], McLeod, Weisz, Wood [23] and Abar, Carter, Winsler [24]. In these researches, in linewith the present investigation, mental disorders and emotional problems including stress, depression and obsessive-compulsive disorder had a negative relation with adolescents within authoritative style of parenting and a positive significant relation with adolescents nurtured with authoritarian and permissive styles of parenting.

In order to express this finding, it can be explained that close relationships of child with his/her parents enables the child to trust on $\mathrm{him} /$ herself in exploring and discovering the surrounding world, and prepare appropriate circumstances for adolescent to investigate the different ways of communication with the world which can result in a strong feeling of him/herself. In families with authoritative style of parenting, the warm, kind, and receptive environment of the family increases the learning ability of adolescents regarding confronting strategies and makes them strong against the problems. But, authoritarian style of parenting is accompanied by kind of over supporting and this is the factor which prepares the substrate of some mental disorders and problems such as eating disorder, obsessivecompulsive disorder and social phobia. In permissive style, poor-care parenting has direct effects on adolescents' mental health [11]. Finally, regarding the educational compatibility, the results of variance analysis showed that educational compatibility of the students nurtured with authoritative style of parenting was significantly more than the educational compatibility of the students nurtured with authoritarian and permissive styles. It was also shown that educational compatibility of the students nurtured with authoritarian stylewas significantly more than that in the students with permissive style.

This result was in agreement with the findings of Aminabadi et al. [25] and Querido et al. [26]. To explain this finding, it can be expressed that in authoritative style of parenting, kind families keep their children far from stress and anxiety by preparing mental peace and comfort, motivate them to make progress, prevent them from getting negative behavior and cause their children's talents become realized and active by preparing motivating environment. But, extreme inhibition in authoritarian parents results in their children's weaker educational performance in comparison with children nurtured with authoritative style. In explaining the higher educational compatibility of the students nurtured by authoritarian parents, in comparison with those who were nurtured by permissive parents, it can be said that with respect to the fact that authoritarian parents apply more inhibition and control on their children in comparison with permissive ones, probably their more perception of inhibition can be impressive on better educational progress of the students nurtured under their parenting style.

As the limitations of the present work, we can mention the lack of collaboration of some students, education councils, and schools and using self-reporting tools for measuring research variables. Also, it is suggested to implement the research on high schoolboy students and different parts of the society, and in more extensive level with larger sample size to obtain more valid results. This investigation can be implemented among a sample of adolescents of different ages, in order to specify the effect of parenting styles in different ages. In addition to the 
questionnaire, it is proposed to use other methods of data collection such as interview and observation because gathering information should not be just relied on the questionnaire.

\section{Conclusion}

Authoritative style of parenting, which expresses proper interaction along with intimacy, while the control is fair and realistic, has more impression on social, educational and emotional compatibility of the children. one effective way of increasing the compatibility of children is to create an emotional safe environment so that the child can talk with parents about the freedom and confidence of her feelings. these parents, while logically controlling their children, expect them to be fair and reasonable, although these parents respect their children's arguments and decisions, but generally give solid reasons for their guidance. This style undoubtedly leads to a higher level of social adjustment in children, in contrast to the other two styles (permissive and authoritarian). Therefore, considering the importance of today's societies for the survival of the family and the mental health of the community, and considering the impact of parenting styles on mental health of students, it seems to be necessary to educate parents and raise their awareness in this area, to improve the parenting style used in children's education, and finally to improve the interaction of parents with their children.

\section{Acknowledgement}

We are grateful for the support of the Khorasan Razavi general education department and students, managers, teachers and staff of the two educational areas of Mashhad.

\section{Contribution}

Study design: TK, FN, MD

Data collection and analysis: TK, FN, MD

Manuscript preparation: TK, FN, MD

\section{Conflict of Interest}

"The authors declare that they have no competing interests."

\section{Funding}

The author (s) received no financial support for the research, authorship and/or publication of this article.

\section{References}

1- Ghanad F, Yonesi J, Azkhosh M. Predict the propensity to marry among perceived parenting styles and cognitive styles associated and independent the field. [dissertation]. Proceedings of the Sixth Seminar of student mental health 2012. pp: 741-5.

2- Baker C, Hoerger M. Parental child-rearing strategies influence self-regulation, socio-emotional adjustment and psychology in early adulthood: Evidence from a retrospective cohort study. Pers Individ Dif2012; 52(7): 800-5.

3- Li Y, Zhang W, Liu J, et al. The role of school engagement in preventing adolescent delinquency and substance Use: a survival analysis. J Adolesc2011; 34(6): 1181-92.

4- Darling N, Steinberg L. Parenting style as context: an integrative model. Psychol Bull1993; 113(3): 487-96.

5- Baumrind D. Current patterns of parental authority. Developmental Psychology Monographs 1971; 4: 1-101. 6- Bakhshi Pour B. Effect of location-based treatment in reducing behavioral problems in children and adolescents Sari school. Unpublished Doctorial [dissertation]. Tehran: Allameh Tabatabai University 2009.

7- Rjabi Gh, Chehardoli H, Atari E. Investigation of the relationship between family functioning and psychological-social class conflict Malayer city high school students. Journal of Education and Psychology2007; 14(1,2): 113-28.

8- Sohrabi P, Hasani A. Ways of parenting and antisocial behavior among adolescent girls. Journal of Psychology2007; 1(14): 75-88.

9- Comijani M, Maher F. Comparison of parenting practices to adolescent conduct disorder and normal adolescents. Knowledge and Research in Psychology2007; 33: 63-94.

10- Syefi M, Safarinia M, Kalantari S. Typology of family parenting (parenting style combined parents) and Its impact intension to drugs in adolescents.Quarterly Journal of Research on Addiction2013;7(25).

11- Ahangranzabi A, Sharifi P, Faragzadeh R. Investigate the relationship between parenting practices and aggression in adolescents Shabestar. The Journal of Cognitive and Behavioral Science2012; 1(1): 1-8.

12- Pakdaman M, Khamesan A, Baratie F. The role of maternal parenting style on adolescent social maturity (bright, slow-paced). Journal of Educational Psychology2011; 8(14): 23-41.

13- Navanbakhsh M, Fathi S. Parenting styles and 
children's social adjustment. Religious Research2011; 22: 33-64.

14- Amanallahifard A, Atari E, Khojastemehr R. Exploring the relationship between family functioning and psychological-social class conflict among high school students in Ahwaz. Research, Consulting (News and Research Services)2009; 8(30): 61-82.

15- Farzigolfazani M, Mohamadesmaeel A, Raofian F, Asgarimoghadam H. Compare parenting style of mothers of children with ADHD, depression, anxiety and obsessivecompulsive mothers of normal children. Research in the Area of Exceptional Children2003; 3(4): 245-64.

16- Ahangranzabi A, Sharifi P, Frajzadeh R. The relationship between parenting styles and adolescent aggression Shabestar city. Journal of Cognitive and Behavioral Science2011; 1-8.

17- Khanjani Z, Smaeeli B, Gholamzadeh M. The role of parenting style in the prediction of anxious thoughts and obsessive-compulsive symptoms in adolescents. Yazd University of Medical Sciences and Health Services2012; 20(1): 39-48.

18- Steinberg L. Adolescence. (3rd edition). New York: McGraw-Hill; 1993.

19- Saefi M, Safariniya M, Kalantari S. Typology of parenting households (combination of parenting styles parents) and their impact on drug trends in adolescent boys. Journal of Substance Abuse2013; 7(25).

20- Hui GC, Yueqin H, Zhaorui L, Baohua L. Associations linking parenting styles and offspring personality disorder are moderated by parental personality disorder, evidence from China. Psychiatry Res2011; 189(1): 105-9.

21- Stover SC, Hall C, McMahon TJ, Easton CJ. Fathers entering substance abuse treatment: An examination of substance abuse, trauma symptoms and parenting behaviors. J Subst Abuse Treat2012; 43(3): 335-45.

22- Urban J, Carelson E, Egeland B, Sroufe LA. Patterns of individual adaptation across childhood. Dev Psychol1991; 3: 445-60.

23- McLeod BD, Weisz JR, Wood JJ. Examining the association between parenting and childhood depression: a meta-analysis. Clin Psychol Rev2007; 27(8): 986-1003.

24- Abar B, Carter KL, Winsler A. The effects of maternal parenting style and religious commitment on self-regulation, academic achievement and risk behavior among african-American parochial college students. $J$ Adolesc2009; 32(2): 259-73.

25- Aminabadi Z, Khodapanahi M, Dehghani M. Mediating role of cognitive emotion regulation in adolescents' perceptions of parenting style dimensions and their academic achievement. Journal of Behavioral Sciences2011; 5(2): 109-17.

26- Querido JG, Warner TD, Eyberg SM. Parenting styles and child behavior in African American families of preschool children. J Clin Child Adolesc Psychol2002; 31(2): 272-7.

Copyright $\odot 2016$ ASP Ins. This open-access article is published under the terms of the Creative Commons Attribution-NonCommercial 4.0 International License which permits Share (copy and redistribute the material in any medium or format) and Adapt (remix, transform, and build upon the material) under the Attribution-NonCommercial terms. 